\title{
R ole of Serum Total PSA (Prostate Specific Antigen) and Free to Total PSA Ratio in the Diagnosis of Carcinoma Prostate
}

\author{
S Ferdousi ${ }^{1}$, MA Alim², Z Ferdous ${ }^{3}$, A K hatun ${ }^{4}$ \\ N Sultana ${ }^{5}$, A Shahnaz ${ }^{5}$, M S Hossain ${ }^{6}$ \\ ${ }^{1}$ Dept of Biochemistry, National Institute of Kidney Diseases \& U rology (NIKDU), D haka; \\ ${ }^{2}$ Dept of U rology, Osmani Medical College, Sylhet \\ ${ }^{3}$ D ept of Biochemistry, N orthern International M edical College, D haka; \\ ${ }^{4}$ Dept of Biochemistry, Dhaka Dental College, Dhaka \\ ${ }^{5}$ Dept of Biochemistry, D haka M edical College, D haka \\ ${ }^{6}$ D ept of Biochemistry, O smani M edical College, Sylhet
}

\section{ABSTRACT}

The objective of the study was to evaluate and compare the role of total and free/total ratio of serum prostate specific antigen level in diagnosing carcinoma prostate. A cross sectional study was conducted at the Department of Biochemistry, Dhaka M edical College (DM C) with collaboration of the Department of Urology, Dhaka Medical College Hospital (DMCH), Dhaka from July 2008 to June 2009. This study was carried out on 60 patients above 50 years of age who attended the Department of U rology, Dhaka M edical College Hospital, complaining of irritative or obstructive lower urinary tract symptoms (LUTS) suspected as clinically benign prostatic hyperplasia (BPH) or cancer prostate. It was aimed to assess the role of total and free/total ratio of serum PSA in diagnosis of BPH and carcinoma prostate with reference to histological diagnosis. All the cases were evaluated by history, physical examination including digital rectal examination, serum prostate specific antigen level, transabdominal/ trans-rectal ultra- sonogram. From all patients, blood sample were collected before digital rectal examination or any per urethral manipulation. Final diagnosis was obtained by histo-pathological examination, specimen being obtained by perrectal biopsy with biopsy-gun. $\mathrm{H}$ istopathological examination detected prostate cancer in 20 out of 60 patient and 17 of these Cap 20 have a total PSA $\leq 4 \mathrm{ng} / \mathrm{ml}$ and only 3 have total $P S A \leqslant 4 \mathrm{ng} / \mathrm{ml}$. 18 of these 20 have free to total ratio $\leqslant 0.16$ and 02 have $\mathrm{f} / \mathrm{t}$ ratio $\leqslant 0.16$. A mong 60 patients, 40 patients were detected $\mathrm{BPH}$ on histopathological diagnosis. 20 of these BPH patient have tPSA $\leq 4 \mathrm{ng} / \mathrm{ml}$ and 20 of BPH have tPSA $\leqslant 4 \mathrm{ng} / \mathrm{ml}$. 38 of $40 \mathrm{BPH}$ patient have $f / t$ ratio $>0.16$ and 2 of 40 patient are $f / t$ ratio $\leqslant 0.16$. Receiver operating characteristic analysis indicated a threshold $\mathrm{f} / \mathrm{t}$ ratio $\leqslant 0.16$ was optimum discriminatory level. The sensitivity of total serum PSA (at cut off value of $>4 \mathrm{ng} / \mathrm{ml}$ ) in correctly differentiating prostatic carcinoma of those who have the condition is $85 \%$, while the specificity of the test in correctly detecting those who do not have the disease is $50 \%$. The PPV is $45.9 \%, N P V$ is $87 \%$ and accuracy is $61.7 \%$. The sensitivity of free/total serum PSA (at cut off value of $0.16 \mathrm{ng} / \mathrm{ml}$ ) in correctly differentiating prostatic carcinoma from $\mathrm{BPH}$ is $90 \%$, while the specificity of the test in correctly detecting those who do not have prostatic carcinoma is $95 \%$. The PPV of the test is $90 \%$ and the NPV of the test is $95 \%$. The overall accuracy of the test is $93.3 \%$. This study showed significant difference of total and free/total ratio of serum prostate specific antigen (PSA) in differentiating benign prostatic hyperplasia (BPH) from carcinoma prostate. Receiver operating characteristic curves showed advantage for the f/t PSA ratio when compared with total PSA in detecting prostate cancer. From the study it may be concluded that total and $\mathrm{f} / \mathrm{t}$ ratio of prostate specific antigen (PSA) is a useful marker in diagnosis of carcinoma prostate. Free/total ratio is more accurate than total PSA.

Key Words: Benign Prostatic Hyperplasia (BPH), Carcinoma Prostate (CaP), Prostate Specific A ntigen (PSA), Free to total ratio of PSA ( $f / t$ ratio) 
S Ferdousi, MA Alim, Z Ferdous, A Khatun, et al.

Introduction

Cancer of prostate is the second commonest malignancy in men ${ }^{1}$. Benign prostatic hyperplasia (BPH) is the most common benign neoplasm in men and its incidence is age related. The prevalence of histological BPH in autopsy studies rises from approximately $20 \%$ in men aged $41-50$ years, to $50 \%$ in men aged $51-60$ years and to over $90 \%$ in men older than 80 years ${ }^{2}$. Wang and his colleagues isolated prostate specific antigen (PSA) from prostate tissue which cast a new light in the diagnosis and prognosis of carcinoma prostate 3 . The simplest way to rule out carcinoma prostate currently is by PSA estimation in conjunction with digital rectal examination (DRE), transrectal ultrasonography (TRUS) and systemic biopsy sampling 4 .

PSA is a $34 \mathrm{kDa}$ serine protease produced by both benign and malignant prostatic epithelial cells ${ }^{5}$. PSA is a chymotrypsin like serine protease produced and secreted at high concentration into seminal fluid, in which its role is to dissolve the gel forming after ejaculation. As a tumor marker, PSA is organ specific rather than tumor associated. It's use as a marker for prostate cancer is based on the fact that only small amounts of PSA leak from the normal prostate into circulation, thus the serum concentrations are normally about one million fold lower than those in seminal plasma. In prostatic disease, the serum concentration of PSA are often elevated due to increased leakage or abnormal secretion of PSA into the circulation. In general the serum concentrations are proportional to the volume of prostatic epithelium, but the release of PSA from cancerous tissue is 30 fold that from the normal prostate and from benign prostatic hyperplasia $(\mathrm{BPH})$ is 3 fold that from the normal prostate ${ }^{6}$. The PSA production by malignant cells is variable and is dependent on the degree of differentiation?.

PSA exists in several forms in serum and is predominantly complexed to protease inhibitors ${ }^{8}$. When PSA is released into the blood
PSA is bound primarily in sera by alpha-1 antichymotrypsin (ACT) and alpha-2 macroglobulin ( $A M G$ ). A smaller fraction of PSA is unbound or free (fPSA) ${ }^{9}$. There are many immunoassays that measure total PSA (tPSA) i.e. PSA complexed to alpha-1 antichymotrypsin plus fPSA. Immune assay techniques have been developed to assess fPSA and PSA bound to ACT but not bound to $A M G{ }^{4}$. The measurement of free PSA and calculation of free to total ratio (f/tPSA) appears to able to reduce the number of unnecessary biopsies, with lower f/tPSA values in patients with prostate cancer than those with $\mathrm{BPH}^{10}$. Reference range of $\mathrm{tPSA}$ is $0-4 \mathrm{ng} / \mathrm{ml}^{11}$. All $M$ en with $\mathrm{tPSA}<2.5 \mathrm{ng} / \mathrm{ml}$ have low probability of having clinically detectable prostate cancer, whereas those with a tPSA $>10 \mathrm{ng} / \mathrm{ml}$ reportedly have a> 50\% chance of having detectable prostate cancer. A limitation to the use of tPSA testing has been its relative lack of specificity within the $4-10 \mathrm{ng} / \mathrm{ml}$ range, a diagnostic grey zone in which prostate cancer is present in $25 \%$ of patients ${ }^{8}$. R ecent reports suggest a significant difference in the f/tPSA in patients with BPH or prostate cancer and the use of $f /$ tPSA ratio may be particularly helpful in patients with a serum total PSA level $<10 \mathrm{ng} / \mathrm{ml}$. Patients with PSA level of $4-10 \mathrm{ng} / \mathrm{ml}$ are diagnostically a problem as there is significant overlap in their total PSA values. For tPSA levels of $4-10 \mathrm{ng} / \mathrm{ml}$, a $\mathrm{f} / \mathrm{tPSA}$ ratio of $<0.16$ had a sensitivity of $53 \%$ and specificity of $76 \% 4$.

A cross-sectional study was conducted to detect total PSA (tPSA) and free/ total ratio of PSA in $\mathrm{BPH}$ and carcinoma prostate patients in population who came for consultation due to urological symptoms. Those patients having total PSA level more than $10 \mathrm{ng} / \mathrm{ml}$, were selected for biopsy and patients with total PSA level between 4-10 ng/ml, among whose free/total PSA ratio less than 0.16 were also selected for biopsy. Rest of the patients were undergone histopathological examination after operation. Total PSA (tPSA) and free/ total ratio of PSA level in carcinoma prostate and $\mathrm{BPH}$ was compared in this study. 


\section{Meterials and Methods}

A cross sectional study was conducted at the Department of Biochemistry, Dhaka Medical College (DMC) with active co-operation of the Department of Urology, Dhaka M edical College Hospital (DMCH), Dhaka, with due permission of authority from J uly 2008 to J une 2009. Study population included the male patients above 50 years of age, who attended the Department of Urology, Dhaka Medical College Hospital, Dhaka, complaining irritative or obstructive lower urinary tract symptoms (LUTS) suspected as clinically benign prostatic hyperplasia (BPH) or cancer prostate. Total 60 cases were selected by purposive sampling technique according to selection criteria. The inclusion criteria were a) $\mathrm{M}$ ale patients above 50 years of age with enlarged prostate, b) Digital rectal examination findings enlarged/nodular/firm/hard prostate, c) Presence of lower urinary tract symptoms such as frequency, urgency, hesitancy, poor flow, incontinence, nocturia etc. Patients were excluded from the study if they had; a)Tender prostate in digital rectal examination, b) Previous history of TURP, c) Enlarged Prostate with renal failure (acute and chronic), d) Heart failure.

Base line study of each patient was evaluated by history, physical examination including digital rectal examination and serum PSA level (total $P S A$, and $f / t$ ratio). Ultra sonogram of prostate was done for echogenicity of prostate. Transrectal ultrasound guided or digital guided biopsy was done by M onopty gun.

Data was compiled and statistical analysis was done using computer based software, Statistical Package for Social Science (SPSS); version 12, using performance of diagnostic test. (ROC) Receiver operating characteristic analysed to compare the performance of tPSA and f/tPSA for diagnosis of carcinoma prostate.

\section{Results}

The present study, intended to determine the value of the ratio of free PSA to total PSA in differentiating carcinoma of the prostate from
$\mathrm{BPH}$, selected 60 cases diagnosed by DRE/TRUS either as carcinoma or BPH. All the patients were investigated for both total and free PSA level. Biopsy material taken from the prostate was sent for histopathological diagnosis. The sensitivity, specificity, positive and negative predictive values, percentages of false positive and false negative and overall accuracies all were computed for total PSA, and free PSA to total PSA ratio against histopathological diagnosis. The findings of the study obtained from data analysis are presented below.

Table I: Distribution of serum total PSA among the patients

Total PSA in $\mathrm{ng} / \mathrm{ml} \mathrm{No}$. of patients

$>109(15 \%)$

4-10 28(46.6\%)

$<423(38.3 \%)$

Table I illustrates the distribution of study subjects by total serum PSA. Of the 60 subjects, about one-third $(38.3 \%)$ of the patients had total serum PSA $<4 \mathrm{ng} / \mathrm{ml}, 46.6 \%$ patients had $4-10$ $\mathrm{ng} / \mathrm{ml}$ and $15.0 \%$ patients had $>10 \mathrm{ng} / \mathrm{ml}$.

Table II: Diagnostic performance of tPSA for Diagnosis of carcinoma prostate

\section{Histopathological Diagnosis}

Total serum PSA N umber of Cardinoma prostate N umber of BPH Total Number $(\mathrm{ng} / \mathrm{ml})$ patients patients patients

\begin{tabular}{lll}
$>417$ & 20 & 37 \\
\hline 403 & 20 & 23
\end{tabular}

Total 20

40

60

Sensitivity $=85 \%$, Specificity $=50 \%$, PPV $=45.9 \%$, NPV $=87 \%$ and Accuracy $=61.7 \%$

Table II shows the diagnostic performance of test result of total serum PSA in differentiating carcinoma prostate from $\mathrm{BPH}$. The sensitivity of total serum PSA (at cut off value of $>4 \mathrm{ng} / \mathrm{ml}$ ) in correctly differentiating carcinoma prostate of those who had the condition was $85 \%$, while the specificity of the test in correctly detecting those who did not have the disease was $50 \%$. The positive predictive value (PPV) of the test was 
$45.9 \%$ and the negative predictive value (NPV) of the test was $87 \%$. The test yielded false+ ves $54.1 \%$ and false-ves $13 \%$. The overall accuracy of the test thus derived from the formula was $61.7 \%$.

Table III: Diagnostic performance of free/total PSA for Diagnosis of carcinoma prostate

\section{Histopathological Diagnosis}

f/t PSA ratio Number of Cardinoma prostate Number of BPH Total Number

patients patients patients

\begin{tabular}{ccc}
0.618 & 2 & 20 \\
\hline 0.1602 & 38 & 40
\end{tabular}

$\begin{array}{lll}\text { Total } 20 & 40 & 60\end{array}$

Sensitivity $=90 \%$, Specificity $=95 \%, \mathrm{PPV}=90 \%$, NPV $=95 \%$ and Accuracy $=93.3 \%$

Table III shows the diagnostic performance of the test result of free/total ratio of serum PSA in differentiating carcinoma prostate from $\mathrm{BPH}$. The sensitivity of free/total serum PSA (at cut off value of $0.16 \mathrm{ng} / \mathrm{ml}$ ) in correctly differentiating carcinoma prostate from $\mathrm{BPH}$ was $90 \%$, while the specificity of the test in correctly detecting those who did not have carcinoma prostate was $95 \%$. The positive predictive value (PPV) of the test was $90 \%$ and the negative predictive value (NPV) of the test was $95 \%$. The test yielded false + ves and false -ves $10 \%$ and $5 \%$ respectively. The overall accuracy of the test thus derived from the formula was $93.3 \%$.

\section{ROC curves for total PSA and $f / t$ ratio of PSA}

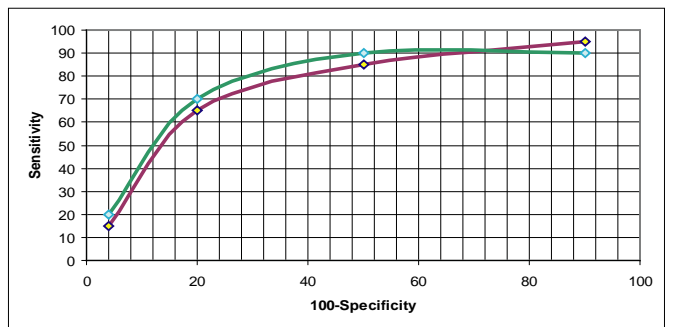

Fig 01: ROC curves for total PSA and $f / t$ ratio of PSA. $G$ reen curve indicate total PSA and red curve indicate $f / t$ ratio of PSA.

The ROC curves had an area of 0.84 for TPSA and 0.95 for $f / t$ PSA ratio, showing that the latter test was better.

\section{Discussion}

The present study was aimed to assess the role of total PSA, and free: total ratio of PSA in diagnosis of $\mathrm{BPH} \&$ carcinoma prostate. All cases were purposively selected from Department of urology of Dhaka Medical College Hospital age above 50 years who has been suffering from lower Urinary tract symptoms due to either benign prostatic hyperplasia or carcinoma prostate.

In the present study, among 60 patients, 23 $(38.33 \%)$ had a total PSA in the normal range of 0 - $4 \mathrm{ng} / \mathrm{ml}$, while $09(15 \%)$ had levels of $>10$ $\mathrm{ng} / \mathrm{ml}$. Patients with serum tPSA of $4-10 \mathrm{ng} / \mathrm{ml}$ which is known as diagnostic gray zone was 28 $(46.67 \%)$. In this study, the patients with $\mathrm{BPH}$ ( $n=40$ ), total PSA level in 20 patients was below $4 \mathrm{ng} / \mathrm{ml}$, in 20 cases it was between 4 to $10 \mathrm{ng} / \mathrm{ml}$. In carcinoma prostate $(n=20)$, total PSA level in 03 case was below $4 \mathrm{ng} / \mathrm{ml}$, in 08 cases between 4 to $10 \mathrm{ng} / \mathrm{ml}$ and in 09 cases it was more than $10 \mathrm{ng} / \mathrm{ml}$. ROC curve had an area of 0.85 for total PSA. At $4 \mathrm{ng} / \mathrm{ml}$ was the best threshold, Sensitivity, specificity, positive predictive value and accuracy of total PSA in differentiating prostatic carcinoma from $\mathrm{BPH}$ were $85 \%, 50 \%, 45.9 \%$ and $61.3 \%$ respectively.

Rietbergen et al12. studied 499 men with total PSA level greater than $4 \mathrm{ng} / \mathrm{ml}$, where he detected $80.2 \%$ prostate cancer, 482 men with total PSA $<4 \mathrm{ng} / \mathrm{ml}$, cancer were found in $19.8 \%$ cases. Transrectal ultrasound guided biopsy was done in all cases. In this study, 23 men with total PSA level $<04 \mathrm{ng} / \mathrm{ml}$, and cancer was detected $03(13 \%)$ cases and 37 men with total PSA level> $04 \mathrm{ng} / \mathrm{ml}$, and cancer was detected 17 (45.9\%) of cases.

A nother study was done by Onur et al ${ }^{9}$. (2003) on 102 patients, of which $61 \mathrm{BPH}$ and 41 carcinoma prostate. Total PSA levels in both group ranged from $0.4 \mathrm{ng} / \mathrm{ml}$ to $30 \mathrm{ng} / \mathrm{ml}$. Total PSA measurement revealed 56 patients with values above $4.0 \mathrm{ng} / \mathrm{ml}$. Of the 61 patients with $\mathrm{BPH}, 20(32 \%)$ had total PSA $4.0 \mathrm{ng} / \mathrm{ml}$ or more, and of the 41 patients with Ca prostate 36 $(87 \%)$ showed elevated total PSA levels. In the present study, among the 40 patients with $\mathrm{BPH}$, $20(50 \%)$ had total PSA more than $04 \mathrm{ng} / \mathrm{ml}$, and among the 20 patients with carcinoma prostate 17 
$(85 \%)$ had total PSA levels more than $04 \mathrm{ng} / \mathrm{ml}$. From this study, it is suggested that total PSA increases in carcinoma prostate than BPH. So total PSA can be used as diagnostic tool in early detection of prostate cancer. But in the diagnostic grey zone (total PSA 4-10ng), total PSA alone cannot diagnose carcinoma prostate. Free to total ratio can be used to detect carcinoma of prostate in such a case.

Christensson et al ${ }^{13}$. determined that ratio of free to total PSA in patients with carcinoma prostate is significantly lower than in men with $\mathrm{BPH}$. $\mathrm{K}$ linger et $\mathrm{al}^{1}$. showed that free: total PSA ratio was better diagnostic marker than total PSA. Luderer et al ${ }^{14}$. carried a study on 181 patients and free/total ratio PSA threshold was 0.20. They showed that sensitivity and specificity of free/total ratio were $87 \%$ and $52 \%$ respectively. Recker et al ${ }^{15}$. on 333 consecutive patients. They showed that free to total PSA ratio had a higher specificity than total PSA at all sensitivity level (91\%). Sensitivity, specificity and positive predictive value at a total PSA threshold of $4 \mathrm{ng} / \mathrm{ml}$ were $88 \%, 57 \%$ and $40 \%$ respectively. At the same sensitivity of $f / t$ PSA, the specificity and PPV were $66 \%$ and $45 \%$ respectively. Wolff et al ${ }^{11}$. studied on 105 patients and found f/tPSA was better at discriminating between patients with $\mathrm{Ca}$ prostate and those with BPH than was tPSA. The $f / t P S A$ threshold was 0.14 , the specificity was $80 \%$ and the sensitivity $84 \%$; the overall accuracy of the test was $82 \%$. The ROC curve has an area of 0.71 for total PSA and 0.85 for $\mathrm{f} / \mathrm{t}$ ratio, showing the latter test is better. In this study, at threshold of $4 \mathrm{ng} / \mathrm{ml}$, sensitivity, specificity and PPV of total PSA were $85 \%, 50 \%$ and $45.9 \%$ respectively but in case of free to total ratio of PSA, at threshold 0.16 , these values were $90 \%$, $95 \%$ and $90 \%$. The overall accuracy of total PSA was $(61.7 \%)$ and free to total ratio of PSA was $(93.3 \%)$. The ROC curve has an area of 0.85 for total PSA and 0.95 for $\mathrm{f} / \mathrm{t}$ ratio. So this study is compatible with the above mentioned studies.
A study was done by A kdas et al ${ }^{16}$. studied 69 patients of age range 57-86 years. At the threshold 0.15 of free to total PSA ratio, in the diagnosis of prostatic carcinoma, the sensitivity, specificity, PPV and NPV were $76 \%, 77 \%, 52 \%$ and $91 \%$ respectively. In the present study, at the threshold of 0.16 of free to total PSA ratio, in the diagnosis of prostatic carcinoma and $\mathrm{BPH}$, the sensitivity, specificity and PPV were 90\%, 95\% and $90 \%$ respectively. So our study was compatible with the study done by A kadas et al ${ }^{16}$.

From the above study, we can suggest that total PSA along with free to total ratio can be used in early detection of prostate cancer and may play important role in reducing biopsy.

From the study, it may be concluded that serum total and $\mathrm{f} / \mathrm{t}$ ratio of prostate specific antigen (PSA) is a useful marker in diagnosis of carcinoma prostate. Free/total ratio is more accurate than total PSA .

\section{References}

1. Klingler $H C$, Woo $H$, Rosario D, Cutinha PE, Anderson J, Ward AM et al. 1998, 'The value of prostate specific antigen (PSA) density and free: total PSA ratio in selecting patients with a normal digital rectal examination and intermediate total PSA levels for further investigation', $\mathrm{Br} J$ Urol, vol. 82, pp. 393- 397.

2. Narayan P, Neoplasm of the prostate gland', in Tanagho EA, M c Annich JW, (ed), Smith's General Urology, 16th edition M CGraw Hill, San Francisco 2004; 392-433.

3. Stamey TA and MC Neal JE. A denocarcinoma of prostate' in walsh PC, Retic $A B, V$ aughan ED, W ein AJ, (ed.), Campbell's U rology, 8th edn, WB Saunders Company, Philadelphia 1992; 4: 30143018.

4. Leung HY, Lai LC, Day J, Thomson J, Neal DE \& Hamdy FC. Serum free prostare specific antigen in the diagnosis of prostate cancer, B J U rol 1997; 80: 256-259.

5. Ellis WJ \& Brawer MK. PSA in benign prostatic hyperplasia and prostatic intraepithelial neoplasia, U rologic Clinics of N orth A merica 1997; 20: 621- 625.

6. Stenman UH. Prostate specific antigen, clinical use and staging, an overview, Br J U rol 1997; 79: 53-60. 
S Ferdousi, M A Alim, Z Ferdous, A K hatun, et al

7. Salam MA. Principles \& Practice of Urology: A Comprehensive Text, 1st edn, MAS Publication, Bangladesh 2002, 635-664.

8. Kehinde EO, Sheikh M, Mojimony OA, Francis I, Anim JT, Nkansa-Dwamena $D$ et al. High serum prostate specific antigen level in the absence of prostate cancer in M iddle-Eastern men, the clinicians dilemma, BJU int 2003; 91: 618-622.

9. Onur R, Ilhan N, Orhan I \& IIhan N. Increased discrimination between benign prostatic hyperplasia and prostate cancer with equimolar total prostate specific antigen measurement', World J U rol 2003; 21: 43-47.

10. Taille A de la, Houlgatte A, Houdelette P, Goluboff $E T$, Berlizot $P \&$ Ricordel I. Influence of free to total prostate specific antigen variability on the early diagnosis of prostate cancer', a comperative study of three immunoassays, Br J U rol 1998; 82: 389- 392.

11. W olff J M, Borchers H, Effert PJ, Habib FK \& J akes GJ. Free to total prostate specific antigen serum concentrations in patients with prostate cancer and benign prostatic hyperplasia', $\mathrm{Br} J$ Urol 1996; 7: 409-413.

12. Rietbergen JBW, Kranse R, Kirkels WJ, Koning $H J D \&$ Schroder FH. Evaluation of prostate specific antigen, digital rectal examination and transrectal ultrasonography in population-based screening for prostate cancer: improving the efficiency of early detection, Br J U rol 1997; 75: 317-324.
13. Christensoon $A$, Bjork $T$, Nilsson $O$, Duhlen $U$, $M$ atikainen MT, Cockett ATK et al. Serum prostate specific antigen complexed to alpha 1 antichymotrypsin as an indicator of prostate cancer, J U rol 1993 15: 100-105.

14. L uderer $A A, C$ hen $Y T \&$ Soriano TF. M easurement of the Proportion of Free to Total Prostate Specific Antigen improves diagnostic performance of Prostate Specific Antigen in the diagnostic gray zone of total Prostate Specific A ntigen', U rology 1005; 46:187-194.

15. Recker $F, K$ wiatkowski $M K$, Piironen $T$, Pettersson K, Goepel $M \&$ Tscholl R. Free- to- total prostatespecific antigen (PSA) ratio improves the specificity for detecting prostate cancer in patients with prostatism and intermediate PSA levels, $\mathrm{Br} J$ Urol 1998; 81: 532-538.

16. A kdas A, Cevic I, Tarcan T, Turkery, Dalaman G $\&$ Emerk $K$. The role of free prostate-specific in the diagnosis of prostate cancer', $\mathrm{Br} J$ U rol 1997; 79: 920- 923. 